\title{
Conservation status and recovery of Podocarpus angustifolius: a threatened tree of Cuba
}

\author{
Ernesto Testé, Majela Hernández, Eldis R. Bécquer \\ Oliver Valle and Luis R. González-Torres
}

\begin{abstract}
The recovery of species' populations is one of the most challenging tasks in conservation, which is why species recovery is most likely to be successful if it involves as many stakeholders as possible. Podocarpus angustifolius, a tree endemic to Cuba, is potentially threatened by overexploitation, deforestation and expansion of exotic species. In December of 2017, in two protected areas containing the only known subpopulations of this species, we recorded the geographical position, height, and diameter at breast height of each individual, and calculated the extent of occurrence (EOO) and area of occupancy (AOO). We recorded a total of 575 individuals, 174 of which were adult (defined as $\geq 6 \mathrm{~m}$ height on the basis of the occurrence of reproductive structures), and most of which occurred in Lomas de Banao Ecological Reserve. The EOO and AOO were $125.8 \mathrm{~km}^{2}$ and $6.0 \mathrm{~km}^{2}$, respectively. All $P$. angustifolius that remain in the wild are within two protected areas, either in rainforest relicts or in coffee plantations. The size structure indicates a growing population. Based on our findings we recommend that $P$. angustifolius should be recategorized from Vulnerable (on the IUCN Red List) and Critically Endangered (on the national Red List) to Endangered, based on criterion D (small population size). We recommend the continued reinforcement of the population at Topes de Collantes Natural Protected Landscape and the continued engagement of local stakeholders for the long-term conservation of this species.
\end{abstract}

Keywords Age structure, Cuba, density, Endangered, Podocarpus angustifolius, population ecology, Red List, recovery

ERnesto Testé (Corresponding author, (D) orcid.org/0000-0001-5399-4203) Jardín Botánico Nacional, Universidad de La Habana, Carretera "El Rocío" km 31122, 19230, Boyeros, Havana, Cuba. E-mail etestelozano@gmail.com

Majela Hernández (D orcid.org/0000-0002-1142-5296) Departamento de Biología Vegetal, Facultad de Biología, Universidad de La Habana, Vedado, Havana, Cuba

Eldis R. BÉCQUER (D orcid.org/0000-0002-8959-150X) Jardín Botánico Nacional, Universidad de La Habana, Boyeros, Havana, Cuba

Oliver VAlle Reserva Ecológica Lomas de Banao, Empresa Nacional para la Protección de la Flora y la Fauna, Banao, Sancti Spíritus, Cuba

Luis R. GonZÁlez-Torres ([D orcid.org/0000-0002-8781-4765) Department of Biology, Douglas College, New Westminster, Canada

Received 2 November 2020. Revision requested 14 January 2021. Accepted 27 January 2021. First published online 9 August 2021.
The recovery of species' populations is one of the most challenging tasks in conservation. For effective recovery a myriad of issues must be addressed, which is why conservationists and other stakeholders from academia, government, and business and local communities need to be engaged in the process. Without full engagement, although species recovery might be achieved, its long-term sustainability would be unlikely, and the time and financial cost of the recovery would significantly increase.

Our team has been working for $>10$ years on the conservation of threatened plants in the Guamuhaya region of Cuba. During this time, we have developed alliances among the local government, the farmers, and the community that have helped us achieve recovery of some threatened species. One that has benefited from these alliances is Podocarpus angustifolius Griseb., an endemic tree currently known only from two locations in the Sancti Spíritus province of central Cuba. Although there are herbarium specimens of the species from seven other localities, in the western provinces of Pinar del Río and Artemisa, the species appears to be extinct there (González-Torres et al., 2015; Mill, 2015).

Podocarpus angustifolius is categorized as Critically Endangered on the national Red List (González-Torres et al., 2015) and Vulnerable on the IUCN Red List (GonzálezTorres \& Gardner, 2013). Both assessments indicate that natural recovery is constrained by the small population and habitat degradation. The major threats to this conifer are overexploitation, deforestation, and the expansion of exotic species (González-Torres et al., 2013, 2015). Here, based on recent surveys, we revise the current conservation status of $P$. angustifolius as a starting point for new conservation actions.

In 2017 and 2018, we conducted a field survey and census of $P$. angustifolius in the Topes de Collantes Natural Protected Landscape and Lomas de Banao Ecological Reserve (Fig. 1), the two known locations of the species. For each individual tree, we recorded the geographical position to an accuracy of $\pm 1 \mathrm{~m}$ (with a GPS), and the height and diameter at breast height (DBH) to an accuracy of $\pm 1 \mathrm{~cm}$. For the census, we did not consider saplings $<20 \mathrm{~cm}$ in height as part of the population, as this cohort has a high mortality (most saplings grow beneath parent trees, limiting development). From the geographical coordinates we calculated the extent of occurrence (EOO, a measure of the spatial spread of the areas occupied by a taxon, commonly measured by a minimum convex polygon) and the area of occupancy (AOO, a scaled metric that represents the area of suitable habitat occupied by a taxon) (Bachman 


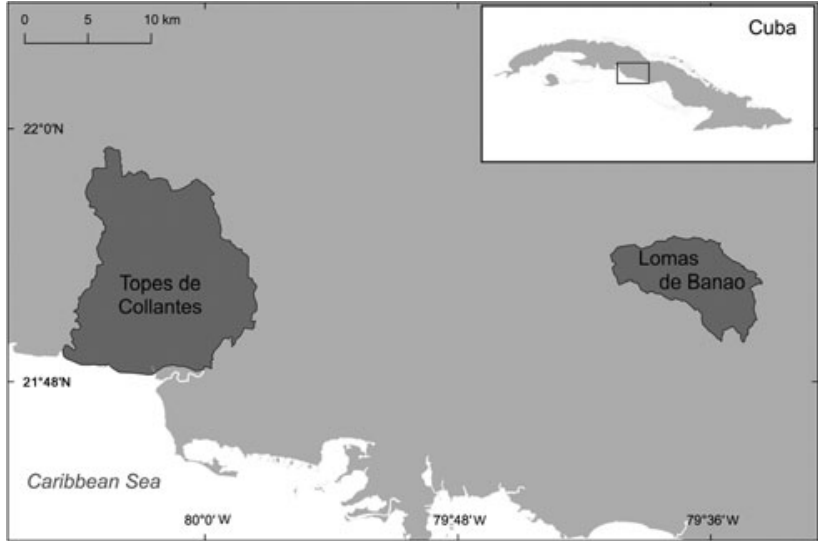

FIG. 1 The location of the Ecological Reserve Lomas de Banao and Natural Protected Landscape Topes de Collantes, in Sancti Spíritus province of Central Cuba.

et al., 2011). We calculated AOO based on a $1 \mathrm{~km}^{2}$ grid. Population density was calculated based on the number of individuals and the AOO. The size structure of the population, which we use as a proxy for age structure, was determined from the height and diameter of the individuals. We defined adult classes based on the height of the smallest individual with signs of reproductive structures found during the survey. Based on these data, we re-evaluated the conservation situation of this species using the IUCN Red List criteria (IUCN, 2012).

All individuals $\geq 6 \mathrm{~m}$ tall were considered adults, as the smallest tree with signs of reproductive structures was $6 \mathrm{~m}$. We located a total of 575 individual trees at altitudes of 623-794 m, of which 174 were adults and 45 were 4-6 m, 570 in well-preserved rainforest without evidence of threats in the Ecological Reserve Lomas de Banao and five in the Natural Protected Landscape Topes de Collantes. We calculated an EOO and AOO of $125.8 \mathrm{~km}^{2}$ and $6.0 \mathrm{~km}^{2}$, respectively, giving a density of 96 individuals $/ \mathrm{km}^{2}$ and 29 adult trees $/ \mathrm{km}^{2}$.

Maximum height and DBH were $23.0 \mathrm{~m}$ (mean $4.47 \pm \mathrm{SD}$ $5.11 \mathrm{~m}$ ) and $44.6 \mathrm{~cm}$ (mean $5.71 \pm S D 8.31 \mathrm{~cm}$ ), respectively. The size structure of the population was characteristic of an expanding population: histograms of both height and DBH have an inverted J shape with $55.5 \%$ and $67.8 \%$ of the individuals, respectively, in the smallest size class, typical of a healthy population (Sahid et al., 2012; Fig. 2). The high concentration of individuals in the smallest class suggests that pollination, regeneration and recruitment are not limiting the population, although this was previously reported to be the case (González-Torres et al., 2013).

Our findings indicate that $P$. angustifolius should be categorized as Endangered rather than as Critically Endangered, its current categorization on the national Red List (GonzálezTorres et al., 2015). Although the small AOO and EOO qualifies the species as Critically Endangered under criterion $\mathrm{B}$, the population cannot be considered severely fragmented because $99 \%$ of the individuals occur at a high density in
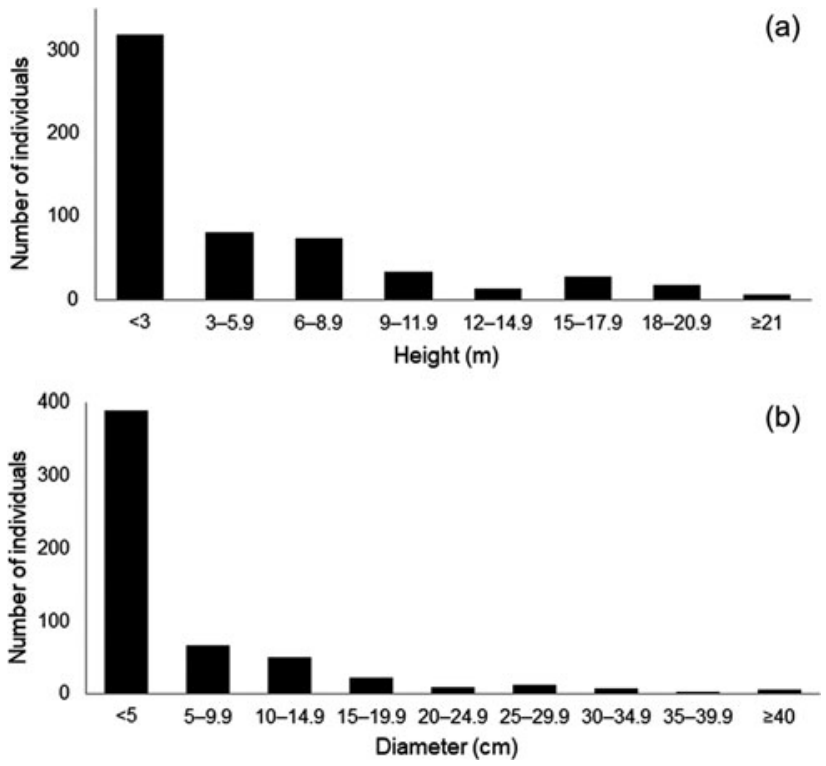

FIG. 2 Frequency histograms of (a) height and (b) diameter at breast height of the 570 Podocarpus angustifolius in Lomas de Banao (Fig. 1).

Lomas de Banao and this subpopulation, its habitat and the quality of its habitat are not severely declining. The small number of mature individuals ( 174 adults) is nevertheless a risk for the species' long-term survival, and fulfils criterion D (small population size) for categorization as Endangered $(<250$ mature individuals). Our assessment therefore suggests the risk of extinction of $P$. angustifolius differs from that of earlier assessments (González-Torres et al., 2013; González Torres \& Gardner, 2013; González-Torres et al., 2015), most likely because our assessment is based on a detailed census whereas earlier assessments were based on rapid field surveys and herbarium records.

The subpopulation of $P$. angustifolius at Lomas de Banao has been managed for conservation purposes since 1998. In Topes de Collantes management of the species began later, in 2010. Since 2017, our team has been working in both protected areas to reinforce the two populations. In Lomas de Banao, we collected saplings (which have a low survival rate in the wild) from beneath adult trees, and cultivated them in nurseries at Lomas de Banao and Topes de Collantes until they attained $50 \mathrm{~cm}$ in height. Most of the saplings were used to reinforce the subpopulation in Topes de Collantes and, to a lesser extent, that in Lomas de Banao. In total, we transplanted 3,708 saplings to the nurseries during 2017-2019, where 400 are still growing. A total of 1,666 saplings, none of which were included in the census reported here, were used to reinforce the subpopulations during 2017-2019 (440 in Lomas de Banao and 1,226 in Topes de Collantes; Plate 1), 484 of which remain alive (a survival rate of $29 \%$ ).

Assuming a continuing establishment rate of $29 \%$ (a conservative estimate, as we would expect the survival rate of 


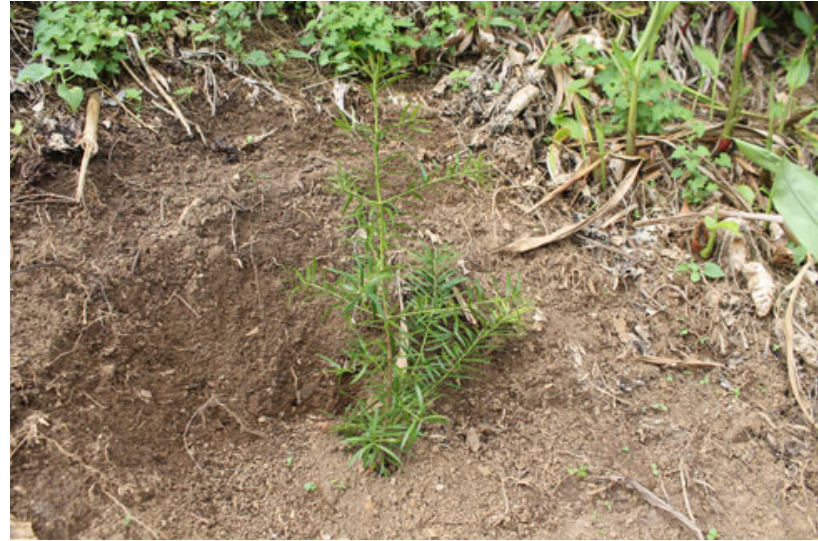

Plate 1 A sapling of Podocarpus angustifolius reintroduced in Topes de Collantes (Fig. 1).

saplings to increase with age), we estimate that in the next 1020 years, c. 140 of the 484 saplings could be recruited into the population. It is possible that as yet undocumented anthropogenic factors could affect older saplings or mature trees to a greater extent (e.g. extraction for ornamental purposes, harvesting of the wood for roofing). As of 10 January 2021, we have an additional 1,700 saplings that will be used for reinforcement during 2021-2022. We intend to continue reinforcing the subpopulation at Topes de Collantes, with the participation of stakeholders, and to initiate the reintroduction of the species in protected areas in the western provinces of Pinar del Río and Artemisa, where the species formerly occurred.

In conserving this narrow endemic tree species, we have learnt three principal lessons. Firstly, once healthy subpopulations have been identified, they can be used as a source of individuals to reinforce other, less healthy subpopulations. In the absence of resources for genetic studies, reasonable levels of genetic diversity can be secured by collecting seeds or plant material from different individuals (Hoban \& Schlarbaum, 2014). This approach can be used to reinforce a population over a relatively short time.

Secondly, entrust local communities with appropriate conservation actions, to enhance their engagement and the sustainability of any actions. In the case of $P$. angustifolius, conservation rangers in Lomas de Banao are in charge of collecting saplings and of maintaining the nursery and reinforcing the population. In Topes de Collantes, local people tend the local nurseries and reinforce the subpopulation, and farmers are reintroducing the tree in their farms. Our role is limited to assisting with the collection of saplings to ensure the diversity of each year's cohort for reinforcement. This alliance between local government, community, farmers, and academia has reduced the cost and time required to implement the recovery strategy for $P$. angustifolius and has secured a close and sustained oversight of the plants in the nursery, in the wild and on farms.
Thirdly, set clear expectations to secure the continued support of stakeholders, conservation actors and supporters. The conservation of long-lived tree species requires patience and constancy. It required c. 10 years for the first $P$. angustifolius to be planted at Lomas de Banao. These lessons learnt while working for the conservation of $P$. angustifolius can be applied to the conservation of other threatened endemic plants of Cuba that have small populations, and also for conservation in other regions.

Acknowledgements This work was conducted with the support of Planta!, the Cuban Botanical Society, the National Botanic Garden (University of Havana), National Enterprise for the Conservation of the Flora and the Fauna, Natural Protected Landscape Topes de Collantes, Ecological Reserve Lomas de Banao, National Center for Protected Areas, Fauna \& Flora International, Arboretum Wespelaar, Fondation Franklinia, and Whitley Fund for Nature. We thank Norlys Albelo and José Luis Moscoso for their support in the plant nursery, and Lisbet González-Oliva for comments on the distribution of the species.

Author contributions Study design, fieldwork: all authors; data analysis: ET, MH; writing: ET, LRGT, with help from all other authors.

Conflicts of interest This research was supported in part by Fauna \& Flora International, the publisher of Oryx.

Ethical standards This research abided by the Oryx guidelines on ethical standards. It was conducted in Cuba, the country of residence of the authors, and all legal requirements regarding permits were followed. In the field research we adopted precautions to avoid accidental introduction of invasive and pathogenic organisms, and no specimens were killed for the purposes of this study.

\section{References}

Bachman, S., Moat, J., Hill, A.W., de la Torre, J. \& Scott, B. (2011) Supporting Red List threat assessments with GeoCAT: geospatial conservation assessment tool. ZooKeys, 150, 117-126.

González Torres, L.R. \& Gardner, M. (2013) Podocarpus angustifolius. In The IUCN Red List of Threatened Species 2013. dx.doi.org/10.2305/IUCN.UK.2013-1.RLTS.T191536A18140999.en [accessed 17 August 2020].

González-Torres, L.R., Palmarola, A., Bécquer, E.R., Berazaín, R., Barrios, D. \& Gómez, J.L. (2013) Las 50 plantas más amenazadas de Cuba. Bissea, 7, 4.

González-Torres, L.R, Palmarola, P. \& González-Oliva, L. (2015) Podocarpus angustifolius. Bissea, 9, 550.

Hoban, S. \& Schlarbaum, S. (2014) Optimal sampling of seeds from plant populations for ex-situ conservation of genetic biodiversity, considering realistic population structure. Biological Conservation, 177, 90-99.

IUCN (2012) IUCN Red List Categories and Criteria, Version 3.1. IUCN, Gland, Switzerland, and Cambridge, UK.

Mill, R.R. (2015) Monographic revision of the genus Podocarpus (Podocarpaceae): II. The species of the Caribbean bioregion. Edinburgh Journal of Botany, 72, 61-185.

Sahid, S., Aziz, S., Ahmed, W. \& Shahzad, A. (2012) Population structure, spatial pattern and reproductive capacity of two semi-desert undershrubs Senna holosericea and Fagonia indica in southern Sindh, Pakistan. Pakistan Journal of Botany, 44, 1-9. 